\title{
Condition monitoring experiences of machines in Hungarian Márkushegy underground mine
}

\begin{abstract}
This paper presents the results obtained during the years of vibration and current signature monitoring at the Márkushegy mining plant before its final closure. The large amount of recorded data has been used for a statistical analysis that is useful for deriving conclusions regarding the incidence of different kinds of faults occurring at the main underground and surface equipment of an underground coal mine. The importance of an inter-inspection time period on the capability of monitoring to increase up-times is revealed. The gained experience that is disseminated in the paper could be a valuable guideline for designing the condition-based maintenance of operating mines.
\end{abstract}

Key words: condition-based maintenance, vibration monitoring, current signature inspection, fault prediction

\section{FOREWORD}

The mining plant in Márkushegy, Hungary's last underground coal mine (which had been continuously producing since 1981) was closed in 2016. At the end of the mining activity, complementary activities also ended, the execution of which supported (sometimes being indispensable) the core activity - coal production.

Such an activity was the running of vibration diagnostic measurements for information on the statusdependent maintenance of the units operating in the mine, in production, and transportation.

At the end of the 1990s, the tools of vibration diagnostics were used in the mine to assess the status of the individual units. The actual paper's aim is to disseminate the accumulated knowledge gained and experienced between 2005 and 2016 as result of this activity.

Initially, only the drive units of the belt conveyors in the surface transport flow were supervised. Over the years, the surveillance was expanded to other equipment; this played the same important role in the good operation of the mine. Over the last few years, the following groups of machines were submitted to vibration monitoring and diagnostics:

- belt conveyor drives, both surface and underground operating units,
- sieves,

- breakers (crushers),

- longwall drum shearer-loaders,

- mine hoists,

- ventilators.

\section{MATERIAL AND METHOD}

The extent limitations of the paper do not allow for a presentation of the schemes of measuring the setup for each group of the above listed equipment.

The most important measurement requirements were imposed by the belt conveyor driving unit (electric drives, clutches, gear unit); therefore, we show the measuring set-up layout of this one in Figure 1.

As can be seen, we used several measuring points and directions for the diagnosis of one driving unit. In the case presented in Figure 1, this number is 18 (which is motivated by the extent of the unit and the number of bearings inside).

In Table 1, we summarized the equipment groups listed above with their numbers of units and corresponding numbers of measuring points (directions); this totaled 550 . 


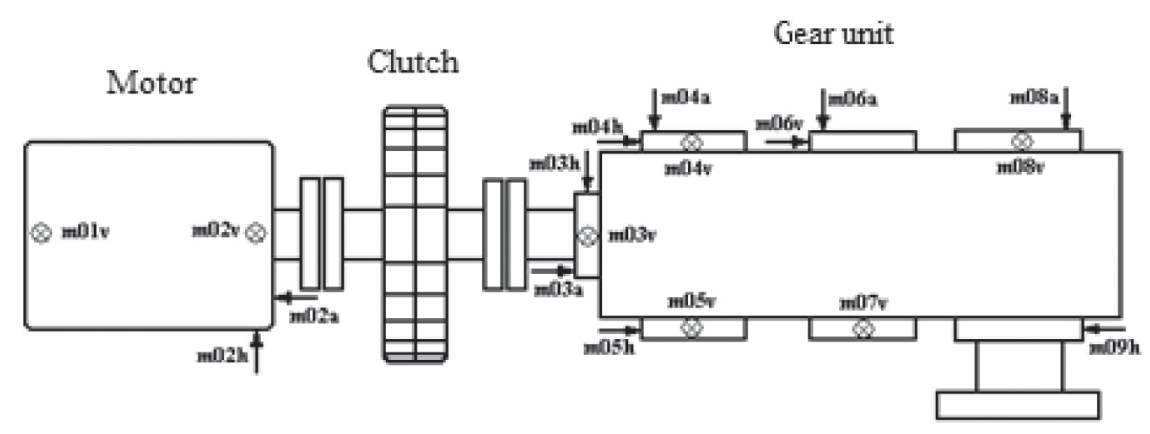

Fig. 1. Measuring set-up layout of belt conveyor driving unit

For each point, at least two spectra were recorded (which means 1100 spectra in all). As the inspection of a unit is performed twice per year (and three times per year for certain units), this accounts for 2200 spectra.

Given the huge number of measurements, the recorded spectra from ten years of monitoring activity represents a strong data warehouse from which valuable information can be gained by using simple statistical tools.

Starting with October 2008, electric current signature diagnosis measurements were performed along with vibration diagnosis measurements. The mine's numerous machines are actuated with three-phase squirrel-cage rotor electric motors.
After a long operating time, damage of the rotor's conductor bars (cage) occurs on these kinds of motors, mainly when they are frequently started under load. As a result, the internal electric resistance of the rotor increases, the characteristic of the motor became weak, and its speed consequently decreases rapidly (even at a reduced load).

This kind of harm is easy to detect by analyzing the motor's current signature. For a detailed description of this issue, see [1] and [2]. This diagnosis monitoring method has been introduced for the critical electric motors as presented in Table 2.

Table 1

Machines examined by vibration diagnosis

\begin{tabular}{|c|c|c|c|c|}
\hline No. & Equipment & Components & $\begin{array}{c}\text { Number } \\
\text { of examined devices }\end{array}$ & $\begin{array}{c}\text { Number } \\
\text { of measuring points }\end{array}$ \\
\hline 1 & $\begin{array}{l}\text { Belt conveyor } \\
\text { driving units }\end{array}$ & $\begin{array}{l}\text { Electric motors } \\
\text { Gear drives } \\
\text { Clutches }\end{array}$ & 21 & 450 \\
\hline 2 & Sieves & $\begin{array}{l}\text { Electric motors } \\
\text { Shaft bearings } \\
\text { Belt drives }\end{array}$ & 2 & 24 \\
\hline 3 & Breakers & $\begin{array}{l}\text { Electric motors } \\
\text { Shaft bearings } \\
\text { Belt drives }\end{array}$ & 2 & 18 \\
\hline 4 & Mine hoists & $\begin{array}{l}\text { Electric motors } \\
\text { Gear drives } \\
\text { Clutches }\end{array}$ & 1 & 18 \\
\hline 5 & $\begin{array}{l}\text { Drum shearer-loaders } \\
\text { Ranging arms }\end{array}$ & $\begin{array}{l}\text { Electric motors } \\
\text { Drum drive gear chain }\end{array}$ & 3 & 30 \\
\hline 6 & Ventilators & $\begin{array}{l}\text { Electric motors } \\
\text { Bearings }\end{array}$ & 3 & 12 \\
\hline
\end{tabular}

Table 2

Electric motors monitored by current signature analysis method

\begin{tabular}{|c|c|c|c|}
\hline Equipment & Rated voltage & Rated power & Number \\
\hline Three-phase electric motor & $1 \mathrm{kV} ; 6 \mathrm{kV}$ & $160-500 \mathrm{~kW}$ & $>80$ \\
\hline
\end{tabular}


The motor's rated power range was $160-500 \mathrm{~kW}$, and its rated voltage was mainly $6 \mathrm{kV}$ (for which the measurements were performed using current measuring transformers). A smaller number of motors were mainly those from the face equipment driving units (at $1 \mathrm{kV}$ voltage and power at the bottom of the range). As they are operating in a harsh environment, their monitoring was very motivated.

\section{RESULTS}

In Tables 3 through 8, the description and number of occurrences of the detected damage are presented.

Table 3

Bearing faults

\begin{tabular}{|c|l|c|l|}
\hline No. & \multicolumn{1}{|c|}{ Equipment } & No. & \multicolumn{1}{|c|}{ Symptom description } \\
\hline 1 & Mine hoist & 1 & Motor is noisy, vibrations \\
\hline 2 & Inclined shaft driving unit & 1 & High vibration level at the fast stage shaft \\
\hline 3 & Belt conveyor drum bearing & 1 & Dry (not lubricated) run \\
\hline 4 & Belt conveyor drum bearing is tightened & 1 & Diagnosed based on temperature increase \\
\hline 5 & $\begin{array}{l}\text { Inclined shaft driving unit fast stage shaft } \\
\text { bearing }\end{array}$ & 1 & High vibration level \\
\hline 6 & Belt conveyor in the 67 roadways & 1 & Shaft is loose in the bearing \\
\hline 7 & $\begin{array}{l}\text { Inclined shaft NU324 electric motor } \\
\text { bearing }\end{array}$ & 2 & Detected by vibration signal \\
\hline 8 & Lubrication improvement proposals & 5 & Improper lubrication consequences \\
\hline 9 & Sieve's motor bearing & 1 & Noisy bearing \\
\hline 10 & Breaker bearing housing destroyed & 1 & $\begin{array}{l}\text { NOT foreseen by diagnosis because of long } \\
\text { inter-inspection time }\end{array}$ \\
\hline 11 & Breaker bearing housing loose & 1 & $\begin{array}{l}\text { Wear of a crushing beam (disc) from breaker } \\
\text { (crusher) rotor }\end{array}$ \\
\hline & Total & $\mathbf{1 6}$ & \\
\hline
\end{tabular}

Table 4

Clutch faults

\begin{tabular}{|l|c|l|}
\hline \multicolumn{1}{|c|}{ Equipment } & No. & \multicolumn{1}{c|}{ Symptom description } \\
\hline Misalignment of coupled shafts & 5 & $\begin{array}{l}\text { High vibration level on both sides } \\
\text { of the coupling clutch }\end{array}$ \\
\hline Unbalanced, loose connection & 11 & Usually sealing rings fault \\
\hline Crackling noise & 1 & \\
\hline Total & $\mathbf{1 7}$ & \multicolumn{1}{|c|}{-} \\
\hline
\end{tabular}

Table 5

Gear faults

\begin{tabular}{|l|c|l|}
\hline \multicolumn{1}{|c|}{ Equipment } & No. & \multicolumn{1}{c|}{ Symptom description } \\
\hline Toothed wheel fault & 6 & Usually bevel gear toothed wheel pair \\
\hline Mine hoist main gear & 1 & Unusual frequency \\
\hline Total & $\mathbf{7}$ & \multicolumn{1}{|c|}{-} \\
\hline
\end{tabular}


Table 6

Broken cage bars

\begin{tabular}{|l|l|l|}
\hline \multicolumn{1}{|c|}{ Equipment } & \multicolumn{1}{|c|}{ No. } & \multicolumn{1}{c|}{ Symptom description } \\
\hline Rotor cage damaged & $12-$ From current signature measurement & Broken bars in the cage \\
\hline $\begin{array}{l}\text { High vibration; } \\
\text { Vibration, rubbing }\end{array}$ & $3-$ From vibration measurement & $\begin{array}{l}\text { Many cage bars broken } \\
\text { and/or bearing fault }\end{array}$ \\
\hline Total & $\mathbf{1 5}$ & - \\
\hline
\end{tabular}

Table 7

Loosening

\begin{tabular}{|l|c|l|}
\hline \multicolumn{1}{|c|}{ Equipment } & No. & \multicolumn{1}{c|}{ Symptom description } \\
\hline Sieves & 1 & Loose bearing support \\
\hline Electric motor & 1 & Resonance of support \\
\hline Gear casing loose & 1 & Fasteners fault \\
\hline Motor casing rubbing & 1 & Rotor-stator contact \\
\hline Shaft eccentricity & 1 & Loose \\
\hline Total & $\mathbf{5}$ & \\
\hline
\end{tabular}

Table 8

Other faults

\begin{tabular}{|l|c|l|}
\hline \multicolumn{1}{|c|}{ Equipment } & No. & \multicolumn{1}{|c|}{ Symptom description } \\
\hline Ventilation problem at L3 motor & 1 & Obstruction by dirt \\
\hline Overheating of K1/1 motor & 1 & Brake not released in operation \\
\hline Torque compensator tighten & 1 & \\
\hline Two driving units' temperature difference & 1 & Thermal imaging \\
\hline Shearer-loader case rubbing & 1 & Cap pressed the bearing \\
\hline Total & $\mathbf{5}$ & \\
\hline
\end{tabular}

\section{CONCLUDING REMARKS}

The conclusions to be drawn from the figures presented in the tables are easier to formulate if one calculates the relative frequencies of each group of faults. These frequencies are summarized in Figure 2.

The first notice is that the greatest frequency ( $\sim 26 \%$ ) belongs to faults that appear in the bearings. It is no coincidence, therefore, that manufacturers of the vibration monitoring devices afford much weight to develop and manufacture support tools (hardware, software) for early diagnosis of the bearings [3].

The second most common fault detected in the studied set $(24.6 \%)$ belongs to the misalignment of clutches. Such a fault, of course, has an impact on the development of the previous group of faults. In fact, the inaccurately set clutches cause overloads on the bearings supporting the coupled shafts [4-6].

Related to the electric motor's diagnosis, it is wellknown that the damage of the rotor cage is a common issue. The mechanical vibrations in this case often have a pulsating electromagnetic force as a source, so the use of electrical measurements brings additional information related to the machine's status $[4,5]$.

The correct choice of control period is extremely important for enhancing the efficiency of the diagnosis. A good example is the fault presented in Row 10 from Table 3 (which was not detected) because the four-month inter-testing period was too long. At this equipment, a reduction in the time between checks would be desirable. 


\section{Fault type incidences}

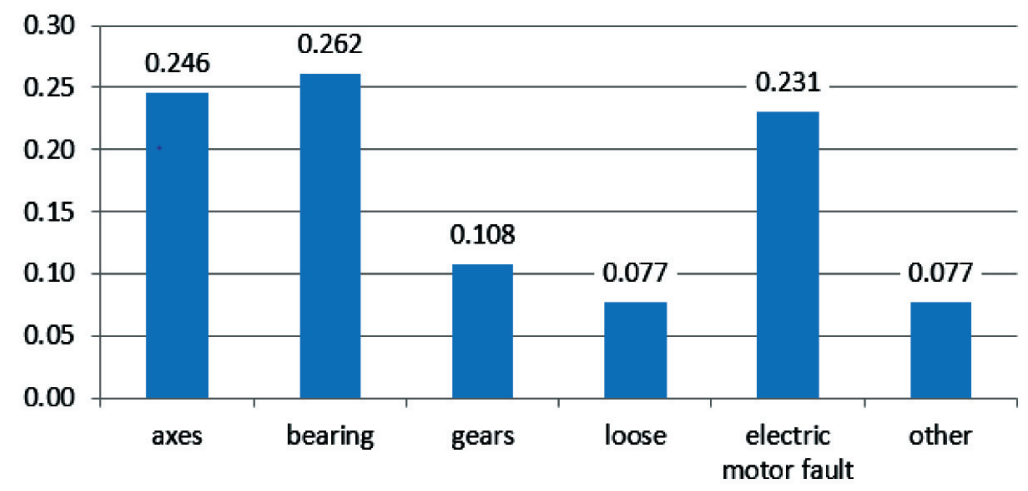

Fig. 2. Relative incidence of faults

We can conclude that the vibration and current signature diagnosis activity performed in the past ten years before the closure of the Márkushegy mine plant contributed to an increase in the availability of the involved equipment and a reduction in the downtimes produced by unexpected faults.

\section{Acknowledgement}

The described work/article was carried out as part of the "Sustainable Raw Material Management Thematic Network - RING 2017,” EFOP-3.6.2-16-2017-00010 project in the framework of the Széchenyi 2020 Program. The realization of this project is supported by the European Union and co-financed by the European Social Fund.

\section{References}

[1] Gilmore R.J., Thomson W.T.: Motor current signature analysis to detect Faults in induction motor drives - fundamentals, data interpretation, and industrial case histories, Proceeding of the Thirty-Second Turbomachinery Symposium, Houston, Texas 2003.
[2] Ladányi G., Ladányi G.: Fault diagnostic of induction motors by using vibration and motor current analysis jointly, GÉP 2013, 3: 16-20.

[3] Brüel \& Kjaer application notes, Machines-Condition Monitoring using Vibration Analysis (The use of Spectrum Comparison for Bearing Fault Detection). A Case Study from Alma Paper Mill, Quebec, Canada (BO 0253-11).

[4] Dömötör F. (ed.): Rezgésdiagnosztika I. Föiskolai tankönyv, Dunaújváros 2008.

[5] Dömötör F. (ed.): Rezgésdiagnosztika II. Föiskolai tankönyv, Dunaújváros 2010.

[6] Brüel \& Kjaer application notes, Vibration measurement in predictive maintenance (BO 0094-11).

GÁBOR LADÁNYI, Assoc. Prof. Eng. Ph.D. Institute of Mining and Geotechnical Engineering Faculty of Earth Science and Engineering University of Miskolc 3515 Miskolc, Egyetemváros gtblaga@uni-miskolc.hu 


\title{
Doświadczenia związane z monitoringiem stanu maszyn w węgierskiej kopalni Márkushegy
}

\begin{abstract}
Artykut przedstawia uzyskane $w$ ciagu kilku lat wyniki monitorowania drgań i podpisu prądu silników w kopalni w Márkushegy przed jej zamknięciem. Do analizy statystycznej użyto duża ilość zarejestrowanych danych, które postużyty do wyciagnięcia wniosków co do częstości występowania różnego rodzaju awarii sprzętu na dole i na powierzchni kopalni węgla. Wykazano znaczenie okresu kontroli dla możliwości monitoringu w celu zwiększenia czasu pracy urzadzeń. Zdobyte doświadczenie, które zostato zaprezentowane $w$ niniejszej pracy, może dostarczyć cennych wskazówek, przydatnych $w$ planowaniu prac konserwacyjnych $w$ kopalni na podstawie oceny stanu.
\end{abstract}

Słowa kluczowe: konserwacja oparta na ocenie stanu, monitorowanie drgań, przeglad podpisu prądu, przewidywanie awarii

\section{WSTEPP}

Zakład górniczy w Márkushegy, ostatnia kopalnia podziemna na Węgrzech, która pracowała nieprzerwanie od 1981 roku, został zamknięty w 2016 roku. Pod koniec działalności górniczej zakończono również działalność uzupełniająca, która wspierała (a czasami była niezbędna) działalność zasadniczą, czyli wydobycie węgla.

W zakres takiej działalności wchodziło prowadzenie pomiarów diagnostycznych drgań w celu uzyskania informacji na temat prac konserwacyjnych zależnych od stanu urządzeń działających w kopalni, w produkcji i transporcie.

Pod koniec lat 90. ubiegłego wieku, w kopalni używano narzędzi diagnostyki drgań do oceny stanu poszczególnych urządzeń. Faktycznym celem niniejszej prezentacji jest upowszechnienie wiedzy i doświadczeń zdobytych w wyniku tych działań w latach 2005-2016.

Początkowo nadzorowano tylko urządzenia napędowe przenośników taśmowych w przepływie transportu na powierzchni. $\mathrm{Z}$ biegiem lat, nadzorem objęto inne urządzenia, odgrywające równie ważną rolę w sprawnym funkcjonowaniu kopalni. W ciągu ostatnich kilku lat monitoringowi drgań i diagnostyce zostały poddane następujące maszyny:

- napędy przenośników taśmowych, zarówno na dole, jak i na powierzchni,

- sita,

- kruszarki,

- bębnowe kombajny ścianowe,

- wyciągi kopalniane,

- wentylatory.

\section{MATERIAŁY I METODOLOGIA}

Zakres niniejszego referatu nie pozwala na przedstawienie schematów konfiguracji pomiarów dla każdej grupy wyżej wymienionego sprzętu.

Najważniejsze wymagania pomiarowe zostały narzucone na zespół napędowy przenośnika taśmowego (napędy elektryczne, sprzęgła, przekładnia), w związku z czym przedstawiamy ten schemat konfiguracji na rysunku 1.

Jak widać, do diagnozy jednego zespołu napędowego zastosowano kilkanaście kierunków i punktów pomiarowych. W przypadku przedstawionym na rysunku 1 , jest ich 18 , co zostało podyktowane rozmiarem zespołu oraz ilością łożysk wewnątrz urządzenia.

$\mathrm{W}$ tabeli 1 podsumowano wymienione wyżej grupy sprzętu, z podaniem liczby zespołów oraz odpowiadającej im liczby punktów pomiarowych (kierunków), których jest w sumie 550 .

Dla każdego punktu zarejestrowano co najmniej dwa widma, tj. 1100 widm. Ponieważ przegląd odbywa się dwa razy rocznie, a w przypadku niektórych urządzeń trzy razy na rok, daje to w sumie 2200 widm.

Zważywszy na ogromną liczbę pomiarów, zarejestrowane widma w okresie dziesięcioletniej działalności monitoringowej stanowią pokaźny zbiór danych, z których można uzyskać cenne informacje, posługując się prostymi narzędziami statystycznymi.

Poczynając od października 2018 roku, dodatkowo, oprócz diagnostycznych pomiarów drgań, wykonano pomiary diagnostyczne podpisu prądu silnika. Liczne maszyny kopalniane i sprzęt są uruchamiane przez trójfazowe klatkowe silniki wirnikowe. 


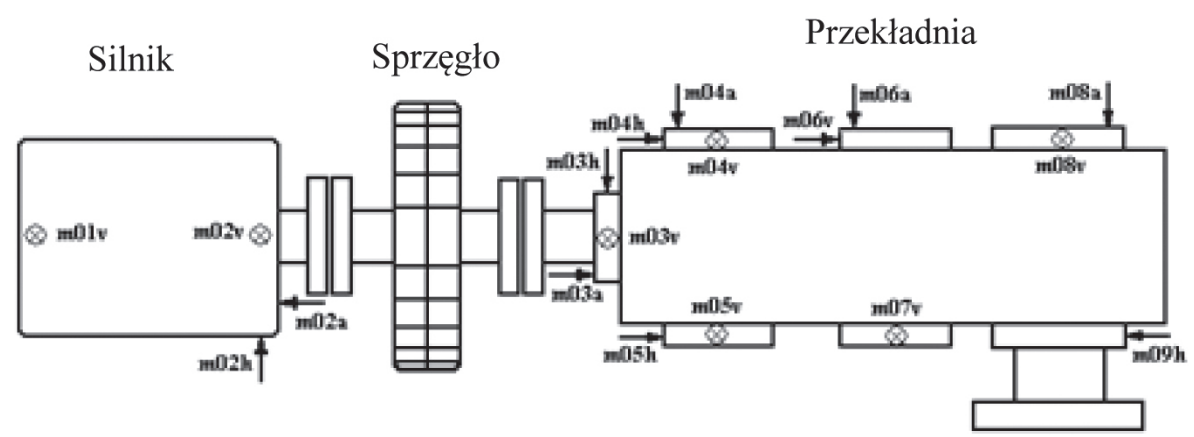

Rys. 1. Układ konfiguracji pomiaru zespotu napędowego przenośnika taśmowego

W tego typu silnikach, po długim czasie działania następuje uszkodzenie prętów klatki, zazwyczaj wtedy, gdy są one często uruchamiane pod obciążeniem. W rezultacie wzrasta wewnętrzny opór elektryczny wirnika, słabną osiągi silnika i co za tym idzie, jego prędkość gwałtownie spada nawet pod zmniejszonym obciążeniem.
Tego rodzaju szkody można łatwo wykryć, analizując podpis prądu silnika. Szczegółowy opis tej kwestii znajduje się w [1] i [2]. Ta metoda diagnostycznego monitoringu została wprowadzona w przypadku najważniejszych silników elektrycznych, tak jak przedstawiono w tabeli 2.

Tabela 1

Maszyny poddane diagnostyce drgań

\begin{tabular}{|c|l|l|c|c|}
\hline Lp. & \multicolumn{1}{|c|}{ Sprzęt } & \multicolumn{1}{c|}{ Elementy } & $\begin{array}{c}\text { Liczba } \\
\text { zbadanych } \\
\text { sztuk sprzętu }\end{array}$ & $\begin{array}{c}\text { Liczba } \\
\text { punktów } \\
\text { pomiarowych }\end{array}$ \\
\hline 1 & $\begin{array}{l}\text { Zespoły napędowe przenośnika } \\
\text { taśmowego }\end{array}$ & $\begin{array}{l}\text { Silniki elektryczne } \\
\text { Napędy przekładniowe } \\
\text { Sprzęgła }\end{array}$ & 21 & 450 \\
\hline 2 & Sita & $\begin{array}{l}\text { Silnik elektryczne } \\
\text { Łożyska wału } \\
\text { Napędy pasowe }\end{array}$ & 2 & 24 \\
\hline 3 & Kruszarki & $\begin{array}{l}\text { Silniki elektryczne } \\
\text { Łożyska wału } \\
\text { Napędy pasowe }\end{array}$ & 2 & 18 \\
\hline 4 & Wyciagi górnicze & $\begin{array}{l}\text { Silnik elektryczne } \\
\text { Napędy przekładniowe } \\
\text { Sprzęgła }\end{array}$ & 1 & 18 \\
\hline 5 & Ramiona kombajnu bębnowego & $\begin{array}{l}\text { Silniki elektryczne } \\
\text { Łańcuch przekładni } \\
\text { napędu bębnowego }\end{array}$ & $\begin{array}{l}\text { Silnik elektryczne } \\
\text { Łożyska }\end{array}$ & 3 \\
\hline
\end{tabular}

Tabela 2

Silniki elektryczne monitorowane metodą analizy podpisu prądu

\begin{tabular}{|l|c|c|c|}
\hline \multicolumn{1}{|c|}{ Sprzęt } & $\begin{array}{c}\text { Napięcie } \\
\text { znamionowe }\end{array}$ & $\begin{array}{c}\text { Moc } \\
\text { znamionowa }\end{array}$ & Liczba \\
\hline $\begin{array}{l}\text { Trójfazowy silnik } \\
\text { elektryczny }\end{array}$ & $1 \mathrm{kV} ; 6 \mathrm{kV}$ & $160-500 \mathrm{~kW}$ & $>80$ \\
\hline
\end{tabular}


Zakres mocy znamionowej silników, dla których wykonano pomiary przy użyciu transformatorów mierzących prąd wynosił 160-500 kW, a ich napięcie znamionowe sięgało zwykle $6 \mathrm{kV}$.

Mniej silników pochodziło z zespołów napędowych sprzętu - ich napięcie wynosiło $1 \mathrm{kV}$, a moc kształtowała się w dolnym zakresie. Ponieważ silniki te pracu- ją w ciężkich warunkach, ich monitorowanie było jak najbardziej uzasadnione.

\section{WYNIKI}

W tabelach 3-8 przedstawiono opis i liczbę przypadków wykrytego uszkodzenia.

Tabela 3

Awarie łożyska

\begin{tabular}{|c|l|c|l|}
\hline Lp. & \multicolumn{1}{|c|}{ Sprzęt } & Liczba & \multicolumn{1}{|c|}{ Opis symptomów } \\
\hline 1 & Wyciag górniczy & 1 & Silnik jest głośny, wibruje \\
\hline 2 & Zespół napędowy szybu pochylonego & 1 & $\begin{array}{l}\text { Wysoki poziom drgań w szybkiej fazie ruchu } \\
\text { wału }\end{array}$ \\
\hline 3 & Łożysko bębna przenośnika taśmowego & 1 & Suchość (brak smarowania) \\
\hline 4 & Naciąg bębna przenośnika taśmowego & 1 & Diagnoza na podstawie wzrostu temperatury \\
\hline 5 & $\begin{array}{l}\text { Łożysko wału szybkiej fazy zespołu } \\
\text { napędowego szybu pochylonego }\end{array}$ & 1 & Wysoki poziom drgań \\
\hline 6 & Przenośnik taśmowy w 67 chodnikach & 1 & Wał jest luźny w łożysku \\
\hline 7 & $\begin{array}{l}\text { Łożysko silnika elektrycznego szybu } \\
\text { pochylonego NU324 }\end{array}$ & 2 & Wykrywany przez sygnał wibracji \\
\hline 8 & Propozycje ulepszeń smarowania & 5 & Konsekwencje niewłaściwego smarowania \\
\hline 9 & Łożysko silnika sita & 1 & Głośne łożysko \\
\hline 10 & Zniszczona obudowa łożyska kruszarki & 1 & $\begin{array}{l}\text { Usterka nieprzewidziana diagnozą z uwagi na } \\
\text { długi czas między przeglądami }\end{array}$ \\
\hline 11 & $\begin{array}{l}\text { Obluzowana obudowa łożyska } \\
\text { kruszarki }\end{array}$ & 1 & Zużycie tarczy kruszącej wirnika kruszarki \\
\hline & W sumie & $\mathbf{1 6}$ & \\
\hline
\end{tabular}

Tabela 4

Awarie sprzęgiel

\begin{tabular}{|c|c|c|}
\hline Sprzęt & Liczba & Opis symptomów \\
\hline Niewspółosiowość wałów sprzężonych & 5 & $\begin{array}{l}\text { Wysoki poziom drgań po obu stronach } \\
\text { sprzęgła }\end{array}$ \\
\hline Niewyważone luźne połączenie & 11 & \multirow{2}{*}{$\begin{array}{l}\text { Zwykle występuje usterka pierścieni } \\
\text { uszczelniających }\end{array}$} \\
\hline Trzaski & 1 & \\
\hline W sumie & 17 & - \\
\hline
\end{tabular}

Tabela 5

Awarie przekładni

\begin{tabular}{|l|c|l|}
\hline \multicolumn{1}{|c|}{ Sprzęt } & Liczba & \multicolumn{1}{c|}{ Opis symptomów } \\
\hline Usterka koła zębatego & 6 & $\begin{array}{l}\text { Zazwyczaj para kół zębatych przekładni } \\
\text { stożkowej }\end{array}$ \\
\hline Główna przekładnia wyciągu górniczego & 1 & Nienormalna częstotliwość \\
\hline W sumie & 7 & - \\
\hline
\end{tabular}


Tabela 6

Złamane pręty klatki

\begin{tabular}{|l|l|l|}
\hline \multicolumn{1}{|c|}{ Sprzęt } & \multicolumn{1}{c|}{ Liczba } & \multicolumn{1}{c|}{ Opis symptomów } \\
\hline $\begin{array}{l}\text { Zniszczona klatka } \\
\text { wirnika }\end{array}$ & $12-$ Z pomiaru podpisu prądu silnika & Złamane pręty w klatce \\
\hline $\begin{array}{l}\text { Wysokie drgania; } \\
\text { Drgania, tarcie; }\end{array}$ & $3-$ Z pomiaru drgań & $\begin{array}{l}\text { Dużo złamanych prętów } \\
\text { klatki i/lub awaria łożyska }\end{array}$ \\
\hline W sumie & $\mathbf{1 5}$ & \multicolumn{1}{c|}{} \\
\hline
\end{tabular}

Tabela 7

Obluzowanie

\begin{tabular}{|l|c|l|}
\hline \multicolumn{1}{|c|}{ Sprzęt } & Liczba & \multicolumn{1}{c|}{ Opis symptomów } \\
\hline Sita & 1 & Luźne podparcie łożyska \\
\hline Silnik elektryczny & 1 & Rezonans podparcia \\
\hline Obluzowana obudowa przekładni & 1 & Usterka mocowania \\
\hline Tarcie obudowy silnika & 1 & Styk wirnik-twornik \\
\hline Mimośrodowość wału & 1 & Luźny \\
\hline W sumie & $\mathbf{5}$ & - \\
\hline
\end{tabular}

Tabela 8

Inne usterki

\begin{tabular}{|c|c|c|}
\hline Sprzęt & Liczba & Opis symptomów \\
\hline Problem z wentylacją na silniku L3 & 1 & Zatkanie przez brud \\
\hline Przegrzanie silnika K1/1 & 1 & $\begin{array}{l}\text { Hamulec nie zwalnia się w trakcie pracy } \\
\text { urządzenia }\end{array}$ \\
\hline Naciagg kompensatora momentu obrotowego & 1 & - \\
\hline $\begin{array}{l}\text { Różnica temperatur dwóch zespołów } \\
\text { napędowych }\end{array}$ & 1 & Termowizja \\
\hline Tarcie obudowy kombajnu & 1 & Łożysko dociśnięte przez nakrętkę \\
\hline W sumie & 5 & - \\
\hline
\end{tabular}

\section{PODSUMOWANIE}

Wnioski, jakie należy wyciągnąć z danych zaprezentowanych w tabelach, są łatwiejsze do wyciągnięcia, jeżeli przeliczy się względne częstotliwości każdej z grup usterek. Częstotliwości te podsumowano na rysunku 2.

Pierwsza nasuwająca się uwaga to fakt, że największą częstotliwość $(\sim 26 \%)$ obserwuje się w grupie usterek łożyska. Nieprzypadkowo więc producenci urządzeń do monitorowania drgań przykładają dużą wagę do opracowania i produkcji narzędzi pomocniczych (oprzyrządowanie, oprogramowanie) do wczesnej diagnostyki łożysk [3].
Druga powszechnie wykrywana awaria w badanym zestawie $(24,6 \%)$ to niewspółosiowość sprzęgieł. Usterka taka w oczywisty sposób wywiera wpływ na powstanie poprzedniej grupy awarii. Faktycznie, niedokładne ustawienie sprzęgieł powoduje przeciążenia na łożyskach wspierających sprzężone wały [4-6].

W diagnostyce silnika elektrycznego dobrze wiadomo, że uszkodzenie klatki wirnika to powszechny problem. Źródłem drgań mechanicznych w tym przypadku jest często pulsacyjna siła elektromagnetyczna, więc zastosowanie pomiarów elektrycznych dostarcza dodatkowych informacji związanych ze stanem maszyny $[4,5]$. 
Częstość występowania rodzaju usterki

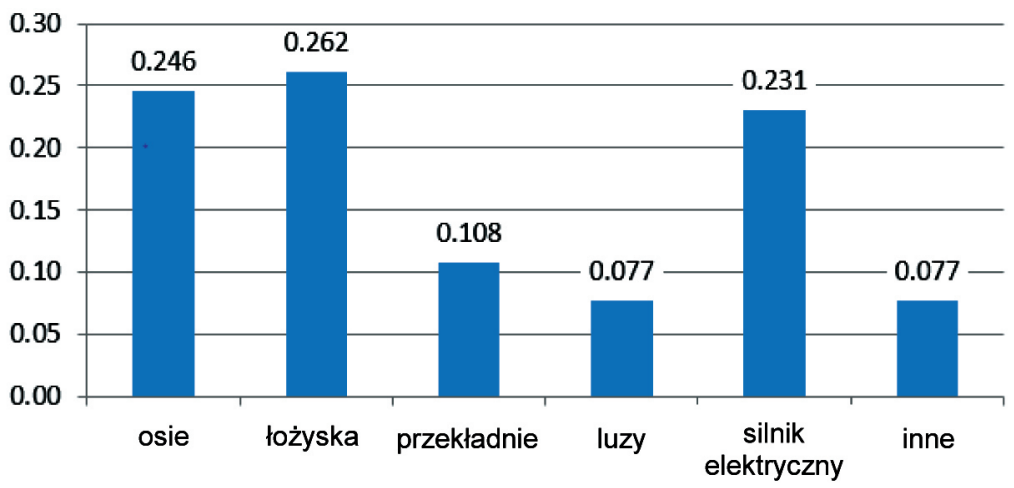

Rys. 2. Względna częstość występowania awarii

Prawidłowy wybór okresu kontrolnego jest niezwykle ważny dla zwiększenia efektywności diagnozy. Dobrym przykładem jest usterka przedstawiona w rzędzie 10 tabeli 3, która nie została wykryta, ponieważ czteromiesięczny okres między przeglądami był za długi. W przypadku tego sprzętu pożądane byłoby skrócenie czasu pomiędzy kontrolami.

Można wywnioskować, że diagnoza oparta na drganiach i analizie podpisu prądu silnika przeprowadzana w ciągu ostatnich dziesięciu lat przed zamknięciem zakładu w Márkushegy przyczyniła się do zwiększenia dostępności zaangażowanego sprzętu i zmniejszenia przestojów powodowanych przez nieoczekiwane awarie.

\section{Podziękowania}

Artykuł został zrealizowany w ramach projektu „Zrównoważone Zarządzanie Surowcami Sieć Tematyczna - RING 2017”, EFOP-3.6.2-16-2017-00010, stanowiącego część Programu Széchenyi 2020. Realizacja tego projektu jest wspierana przez Unię Europejską i współfinansowana przez Europejski Fundusz Społeczny.
Literatura

[1] Gilmore R.J., Thomson W.T.: Motor current signature analysis to detect Faults in induction motor drives - fundamentals, data interpretation, and industrial case histories, Proceeding of the Thirty-Second Turbomachinery Symposium, Houston, Texas 2003.

[2] Ladányi G., Ladányi G.: Fault diagnostic of induction motors by using vibration and motor current analysis jointly, GÉP 2013, 3: 16-20.

[3] Brüel \& Kjaer application notes, Machines-Condition Monitoring using Vibration Analysis (The use of Spectrum Comparison for Bearing Fault Detection). A Case Study from Alma Paper Mill, Quebec, Canada (BO 0253-11).

[4] Dömötör F. (red.): Rezgésdiagnosztika I. Föiskolai tankönyv, Dunaújváros 2008.

[5] Dömötör F. (red.): Rezgésdiagnosztika II. Föiskolai tankönyv, Dunaújváros 2010.

[6] Brüel \& Kjaer application notes, Vibration measurement in predictive maintenance (BO 0094-11).

prof. GÁBOR LADÁNYI

Instytut Górnictwa i Geotechniki

Wydziat Nauk o Ziemi

Uniwersytet $w$ Miszkolcu

3515 Miskolc, Egyetemváros

gtblaga@uni-miskolc.hu 